\title{
RIIMI SUNNIL SÜNDINUD ELUKAS
}

\author{
KRISTIINA ROSS
}

J ärgnevas tuleb juttu ühest eestikeelse lõppriimilise luule algusaastate tõenäoliselt juhuslikust kõrvalsaadusest, mis või kes hiljem iseseisvalt tegutsema on pääsenud ja siiamaani elujõudu paistab ilmutavat.

Eestikeelne lõppriimiline luule tekkis XVII sajandil ning hakkas arenema kahes vormis: juhuluulena ja kirikulaulu tõlkena (üksikud kirikulaulude tekstid on ka kohapeal loodud). Varajasim säilinud eestikeelne juhuluuletus pärineb teatavasti 1637. aastast Reiner Brockmannilt, keda seetõttu peetakse ka eesti kunstluulele alusepanijaks. Esimene lõppriimiline silbilis-rõhuline kirikulaulude väljaanne ilmus 1656. aastal ning selle tõlkijateks olid lisaks tollelesamale Reiner Brockmannile (kes raamatu ilmumise ajaks oli juba surnud) veel Martin Gilläus, Heinrich Göseken ja Georg Salemann. Henrik Visnapuu on püüdnud leida lõppriimi algeid või vähemalt eeldusi juba eesti vanemast rahvalaulust (Visnapuu 1932), Mart Mäger seevastu on otsesõnu väitnud, et lõppriim jõudis eesti luulesse „valmis kujul”, kanoniseeritud täisriimina Brockmanni esimese luuletuse kaudu ja levis seejärel lauluraamatutes rakendatud uuendusliku vormivõttena (Mäger 1971: 129-130). Kaudsetele andmetele tuginedes on küll ka oletatud, et kunstluule ja eriti kirikulaulu vorminõudliku eestikeelse tõlke traditsioonid võisid olla palju pikemad ja ulatuda vahetult reformatsioonijärgsesse või koguni veelgi varasemasse aega (Neithal 2005). Säilinud tekstide põhjal saab lõppriimi teket eestikeelses luules jälgida siiski alles alates Brockmanni esimesest juhuluuletusest ja 1656. aasta lauluraamatust.

Nagu M. Mäger viidatud käsitluseski rõhutab, olid eestikeelse luule edasise arengu seisukohalt olulised just kirikulaulud (Mäger 1971: 130). Erinevates keeltes viljeldud juhuluule vormieksperimendid puudutasid vaid saksaja ladinakeelse haritlaskonna siseringi. Kirikulaul jõudis kõigi eestlasteni ja suunas kogu eestikeelse luule uude värsisüsteemi. Eesti rahvalaul oli seni tuginenud kvantitatiivsele süsteemile, mõtteparallelismile ja algriimile. Kirikulaulude (kaas)mõjul hakkas XVII ja XVIII sajandil tekkima uus, silbilisrõhuline, stroofiline ja lõppriimiline rahvalaul ning sellisena arenes XVIII ja XIX sajandil ka kogu eestikeelne kunstluule. Selle arengu alusepanija, esimese värsistatud lauluraamatu kultuuriloolist tähendust ja ka keelelist külge on paaris käsitluses selgitatud (Masing, Soosaar 1999 [1956]; Masing 1999 [1962]; Salu 1949; Võõbus 1970), kuid kindlasti vääriks esimene lauluraamat edaspidi põhjalikku vormianalüüsi.

Luterlikus jumalateenistuses oli kirikulaulul varasemast palju tähtsam sisuline roll. Kui seni oli laul olnud jumalateenistuse ebaoluline kaasnähtus, siis nüüd sai sellest keskne komponent, mille kaudu kogudus liturgias aktiivselt osales. Vormiliselt ei tekkinud saksakeelne luterlik kirikulaul aga mitte tühjale kohale, vaid kasvas välja vanadest kirikulauludest ja rahvalikest ilmalikest lauludest, eriti meistersingerite traditsioonist, ning paljude laulu- 
de stroofika ja riimid olid üles ehitatud meistersingerite reeglitele vastavalt (Rupprich 1973: 252). Eesti keeles salmimise ja riimimise varasem traditsioon puudus ja kirikulaulude tõlkijail tuli reeglid mehhaaniliselt saksa keelest üle kanda. Saksa värsimõõtu ja stroofikat tuli järgida juba selleks, et tõlked oleksid originaalidega samal viisil lauldavad. Kuid 1624. aastal ilmunud Martin Opitzi värsiõpetuse mõjul suhtuti 1656. aasta lauluraamatu tõlgetes tegelikult värsimõõtu ja riimide puhtusse rangemaltki kui varasemast ajast pärit saksa originaalides (mida vähemalt Martin Gilläus tagantjärele kahetseb - Masing 1999 [1962]: 93). Pigem anti järele sisus kui vormis, nii et paiguti on mõni salm vaevu mõistetav.

Puhtalt riimuvaid sobiva sisuga täistähenduslike sõnade paare, nagu taiwas : waiwas jms, oli vähe ja need kulusid ruttu. Seetõttu moodustavad suure osa esimese lauluraamatu riimidest ootuspäraselt üsna sisutühjad sõnapaarid, nagu (tänapäevases ortograafias) ees : sees, sind : mind, seda : teda jms. Osa riimide korral pole päris selge, kuidas need XVII sajandi keskpaiga autorite keeletajus täpselt pidid kõlama, aga loomulikult leidub esimeses lauluraamatus siiski ka hulgi irdriime, nagu keip : woip, löidap : hoidap, (Jordani) Jöhst : (Johann'se) Kehst jms. Riimide varieerimiseks kasutati mitmeid nippe. Riimidesse kaasati kaasrõhuliste sõnaosade ühtelangemised - nii juhud, kus kokku langevad pearõhulise ja kaasrõhulise silbi häälikud (mah : kaswada), kui ka need, kus kokku langevad kahe kaasrõhulise silbi häälikud omavahel (kawwalast : lehhembast). Selle üle, kas kaasrõhuliste silpide omavahelised ühtelangemised annavad korraliku riimi või mitte, on hiljem vaieldud. Joel Sang ja Ülle Viks näiteks arvasid niisugused juhud oma riimisõnastikust välja (Sang, Viks 1991: 615), kuid esimeses lauluraamatus olid kaasrõhuriimid aktsepteeritud ja selline mööndus andis riimijaile palju vabamad käed. Nõnda osutusid omavahel riime andvaks muu hulgas näiteks kõik kahesilbilise tüvega verbide mineviku kesksõnad, nagu sündinut : huckatut jms, misläbi võimalike riimipaaride hulk kasvas tohutult.

Aga otsiti ka loomingulisemaid lahendusi. Eriti äratab tähelepanu üks sõnaühend või liitsõna, mis näibki olevat loodud ladusa riimi tekitamiseks. Nimelt on neljas Heinrich Gösekeni ja ühes Georg Salemanni tõlkes pandud suure esinemissagedusega tegusõna olema vorm on riimuma sõnaga põrgukonn. Nt Gösekenil (laulu „Vom Himmel kam der Engel Schar” 4. salmis) Ep teep nüdt Kurja Pörgko-Kon / Et Jummal meite jures on (Gesangbuch 1656: 162), Salemannil (laulu „Ein feste Burg ist unser Gott” 1. salmis): Se wanna Pörgko-Konn / Ni töis sest Weehast on (Gesangbuch 1656: 339). ${ }^{1}$

Saksa originaalides vastab eesti põrgukonnale kurat, kelle tähistamiseks kasutatakse vastavates salmides sõnu Teuffel 'kurat', (Böse) Feind '(kuri) vaenlane', Höllenbrand 'põrguline' ('keegi, kes on väärt põrgus põlema' - Paul 1966: 316). Saksa kirikulauludes esineb muidki kuradit tähistavaid sõnu, kuid sõnaühendit *Höllenfrosch või *Höllenkröte, mis lubaks pidada eesti põrgu-

1 Ühel korral on Göseken kasutanud kuju Pörgko Konna positsioonis, mis süntaktilise funktsiooni järgi eeldaks samuti nominatiivi: Sa tah'xit kahs weel tenna / Mind hoida Armo kaas / Et mitt se Pörgko Konna / Woip tehha Kurja tahs (Gesangbuch 1656: 86). Võimalik, et siingi on siiski silmas peetud sama väljendit ning $a$ on lisatud ainult rütmi ja riimi pärast. Göseken on neljast tõlkijast tõlkinud kõige rohkem laule ning võib-olla just seetõttu torkavad tema tõlgete hulgas kõige enam silma vormisundusest sündinud täitesilpidega sisutühjad fraasid ning muud keelendid, mis on Uku Masingu sõnul „vahel täiesti arusaadamatud” (Masing, Soosaar 1999 [1956]: 85). 
konna tõlkelaenuks, ei näi tollane saksa keel kasutavat. Ehkki kärnkonn oli Euroopas tuntud inetuse ja pahelisuse sümbolina, ei tõuse ta kuradi võimaliku kehastusena teistest loomadest kuigivõrd esile (Valk 1994: 130-131). Martin Luther on küll kuradit võrrelnud kärnkonnaga (Grimm, Deutsches Wörterbuch sub Kröte - http://woerterbuchnetz.de/DWB/?sigle=DWB\&mode=Vernetz ung\&lemid=GK14866), kuid vastavat liitsõna või sõnaühendit pole talt registreeritud.

Ilmselt tundus ka eestikeelne põrgukonn juba tõlkijatele enestelegi pisut kahtlane. Igatahes on H. Göseken selle sõna oma 1660. aastal ilmunud grammatika sõnastikust välja jätnud (vt Kingisepp jt 2010), ehkki üldiselt paistavad lauluraamatus leiduvad sõnad seal kajastuvat. Vestluses põrgukonna võimaliku päritolu üle juhtis Kai Tafenau siinkirjutaja tähelepanu seigale, et lauluraamatu järgmise, 1673. aasta trüki anonüümses kriitikas, mille autoriteks Tafenau peab sajandi lõpu keelereformaatoreid Johann Hornungit ja Adrian Virginiust (Tafenau 2011), on halva tõlke ühe näitena toodud muu hulgas ka eespool esimesena tsiteeritud värsirida laulu „Vom Himmel kam der Engel Schar” tõlkest, mis on saksa keelde tagasi tõlgitud kujul „der höllische frosch thut nun kein böses" ('põrgulik konn ei tee nüüd kurja'). Lauluraamatu kriitika oli mõeldud eestimaalaste tõlget naeruvääristama ning oma tagasitõlke kommentaaris ironiseerivad kriitikud just väljendi „höllische frosch” üle. Sellele kriitikale reageeritakse omakorda Eestimaa konsistooriumi kirjas 16. märtsist 1689, milles väljendit höllen-frosch õigustatakse pühakirja autoriteediga, viidates Ilmutuseraamatu kirjakohale (16:13-14), kus rüvedaid vaime on võrreldud konnadega (Piiblikonverentsid 2003: 239-240).

Kõigest sellest jääb mulje, et nii Heinrich Gösekeni kui ka hilisemate kriitikute ning kriitikale vastanute meelest oli põrgukonn imelik ja haruldane sõna, mis oli loodud riimi pärast. Kuna laulude täpsem tõlkekronoloogia pole teada, jääb vaieldavaks, kas riimi on : põrgukonn mõtles välja Göseken ise või tuleks selle loojaks pidada Salemanni. Gösekeni tõlgetes võib seda rohkem esineda lihtsalt selletõttu, et ta tõlkis rohkem laule kui teised.

Kriitikale vaatamata jäi põrgukonn ootuspäraselt sisse ka lauluraamatu kolmandasse trükki 1693. aastal, sest see ilmuski enam-vähem endisel kujul. Keelereformaatorite sõnastatud uuenduslikust põhjaeestikeelsest lauluraamatust 1694. aastal on aga põrgukonn välja visatud ja rohkem teda põhjaeesti lauluraamatutes ei esine. Pietistide toimetatud 1727. aasta lauluraamatus on mõni laul küll taas täiesti ümber sõnastatud, aga sõna põrgukonn enam tagasi pole toodud.

Päriselt see väljend eesti keelest siiski ei kadunud ja XVIII sajandi lõpust ilmub ta koguni sõnaraamatutesse. Esimesena toob selle A. W. Hupel 1780. aastal oma sõnaraamatus märksõna pörgo juures tartukeelsena: pörgo kon - der Teufel. $d$. (Hupel 1780: 245). Ilma paikkondliku viiteta esitab väljendi hiljem F. J. Wiedemann oma sõnaraamatus märksõna konn all: põrgu-k. - Teufel (Wiedemann 1869: vg 372). Liitsõna on kuradi sünonüümina loetletud ka Saareste sõnaraamatus märksõnade KURI ja KURIVAIM all (Saareste 19581963 II: vg 140, 144) ning on ühe tekstinäitega jõudnud kirumissõnana tänapäeva eesti kirjakeele seletussõnaraamatusse: „Kuradi lontrus, vandus Mulla hääletult. Kas sa, põrgukonn, ei mäleta, mis ülesandega sa koosolekule tulid!” H. Angervaks (EKSS: 569). Sõnaraamatu kartoteegis leidub veel paar näidet ilukirjandusest ning kuradi sünonüümina on sõna kirja pandud ka rahvajut- 
tudes (vt nt http://www.muuseum.haapsalu.ee/index.php?option=com_content \&view=section\&layout=blog\&id=12\&Itemid=249).

Kirjeldatu põhjal tekib kaks küsimust. Esiteks: kust võttis Hupel põrgukonna oma sõnaraamatusse, kui seda ei sisalda varasemad sõnaraamatud, millele ta väidab end tuginevat - ei Anton Thor Helle ja Eberhard Gutsleffi 1732. aastal ilmunud sõnaraamat ega J. Chr. Clare ja S. H. Vestringi käsikirjalised sõnaraamatud? Selgub, et lõunaeesti lauluraamatutesse, mille esimene värsistatud versioon (1685) oli tehtud põhjaeesti tõlgete järgi, jäi põrgukonn kahe laulu tõlkesse alles ka teises trükis (1690), mida Adrian Virginius ise parandas ja täiendas, ning püsis seal Hupeli aegadeni (vt nt Tarto-Ma kele Laulu-Ramat 1752: 151, 179) vaatamata sellele, et lõunaeesti keeles ei anna põrgukonn : om puhast riimi. Asjaolu, et F. J. Wiedemann oma sõnaraamatus põrgukonna tartukeelsete sõnade hulka ei arva, lubab spekuleerida, et võibolla jõudis sõna juba esimestest põhjaeesti värsstõlgetest ikkagi rahvakeelde ning jäi sinna kuradi sünonüümina püsima ka siis, kui laulud ise ümber tehti. See sobiks hästi oletusega, et riimilised kirikulaulud said ruttu populaarseks ja mõjutasid rahva keelt ning luuletaju. Võib-olla püsisid vanad tõlked ka ise suulises pärimuses edasi. Eriti võiks seda oletada nende salmide korral, kus vanas tõlkes oli mõni võtmesõna pandud puhtalt riimima, hilisemates tõlgetes aga asendati puhas riim irdriimiga või nihutati võtmesõna üldse riimipositsioonilt välja, misläbi tõlge selguses ja löövuses kindlasti kõvasti kaotas. Just nii läks riimiga põrgukonn : on. Näiteks laulu „Ein feste Burg ist unser Gott" tõlkes asendati puhas riim hilisemates variantides märksa lõdvemaga: Se wanna PörgkoKonn / Ni töis sest Weehast on (Gesangbuch 1656: 339) $\rightarrow$ Se wanna Pahharät / Ke näitis Patto Teed (Laulo Ramat 1694: 127) $\rightarrow$ Se kurri waenlane / Meid wihkab kurjaste (Laulo-Ramat 1727: 223); laulu „Ach Gott wie manches Herzenleid" hilisemas tõlkes tõsteti võtmesõna värsi lõpust ettepoole: So perral Hing ninck Ihho on / Mis woip mul tehha Pörgko-Kon? (Gesangbuch 1656: 339) $\rightarrow$ Ei woi mo külgi putuda / Surm, Kurrat, keige Pattoga (Laulo Ramat 1694: 111).

Selles osas, kas F. J. Wiedemann leidis põrgukonna Hupeli sõnaraamatust ning see jõudis rahvasuhu ja hilisematesse ilukirjanduslikesse tekstidesse alles Wiedemanni kaudu või oli sõna rahvakeeles XVII sajandi teisest poolest peale olemas olnud, võib XVIII ja XIX sajandi kirjaliku pärandi edasine läbitöötamine tuua täpsustusi.

Teiseks tekib küsimus: kuidas on lauluraamatu põrgukonn seotud Kreutzwaldi põhjakonnaga? August Annist oletab, et Kreutzwaldi 1866. aastal ilmunud muinasjutu „Põhjakonn” koletise eeskujuks on olnud rahvusvaheline lendava mao motiiv, kuid et Kreutzwald tahtis luua eestipärasemat tegelast ning ühendas seetõttu „lohe õudsed omadused eestipärase konna kujuga ja laskis selle tulla põhjamaalt, mis nii eesti kui soome rahvauskumuste järgi oli kõige kurja asupaik”. Seejärel küsib Annist: „Miks aga siiski selle koletise nimeks valiti konn ja mitte näiteks koll?" Ja vastab M. J. Eiseni varasemale oletusele (Eisen 1926: 229-230) tuginedes: „Eisenil näib siin õigus olevat, et „konn” tulebki õigupoolest lugeda muljeeritult „kon'n’”, mis tähendab murdeti „koll”. Kreutzwald võis rahvalt kuulda nimetust „kon'n” või merekon'n”” ja seda vääriti mõistes „põhja konnaks” välja arendada, mis pealegi paistis olevat konkreetsem ja eestipärasem" (Annist 1966: 182).

Siin kirjeldatu valguses tundub tõenäone, et ükskõik, kas oli põrgukonn 
läinud lauluraamatutest rahvasuhu või jõudnud kirikulauludest otse ainult Hupeli sõnaraamatusse, igal juhul võis Kreutzwald seda sõna tunda. Ja pigem ilma palataliseerimata, riimuvana sõnaga on, sest Hupeli sõnaraamat palataliseeritud varianti kon 'koll' ei sisalda, vaid toob põhisõnana ainult kon, $G$. konna tähenduses 'der Frosch'. Jõudmaks sõnast põrgukonn sõnani põhjakonn oli vaja ainult kristlikule traditsioonile viitav esikomponent põrgu välja vahetada häälikuliselt sellega sarnase põhja vastu, mis oletatava eestipärasusega sisuliselt paremini sobis. Rahvusvaheline lohe motiiv võis sealjuures muidugi lisainspiratsiooni pakkuda, kuid nimetsi näib põhjakonna otseseks eellaseks olnuvat XVII sajandi vaimulike tõlkijate riimiotsinguist sündinud sõna.

Andrus Kiviräha „Ussisõnades” sooritatud teisendusega on põhjakonnast nüüdseks saanud pärisrahvale sõbralik olend, kes kunagi kõik vaenlased hävitas, aga praegu süüdimatult magab. Miskipärast pälvis just see Kiviräha teos prantslaste tähelepanu ja väidetavasti tõotab selle aasta alguses ilmunud prantsuskeelne tõlge eesti kirjandusele lausa rahvusvahelist edu. Nõnda sobib saksa vaimuliku tõlkeluule värsistamise kõrvalproduktina sugenenud konnaelukas koos kõigi oma hilisemate metamorfoosidega hästi illustreerima baltisaksa pastorite ambivalentset, aga vaieldamatult suurt rolli eesti rahvuskultuuri käekäigus.

\section{Allikad}

Gesangbuch 1656 = Neu Ehstnisches Gesangbuch / Worinnen die Kirchen Gesänge Sel. Hn. Lutheri und aderer Gottseligen Männer in die gewöhnliche Melodeyen und gleiche Reimen verfasset sind. Reval: Adolph Simon.

Gesangbuch 1673 = Neu Eestnisches Gesangbuch / Worinnen die Kirchen-Gesänge Sel. Hn. Lutheri und anderer Gottseligen Männer in die gewöhnliche Melodeyen und gleiche Reimen verfasset sind. Reval: Adolph Simon.

Laulo-Rahmat 1693 = Ehsti-Ma Laulo-Rahmat / Tallo-Rahwa Kohli- nink KirkoLapsede tarbix / kud Jummala Auwux / ninda welja-sähdtut. Rähvli- echk TalLinnas: Christoff Brendeken.

Laulo Ramat 1694 = Ma Kele Laulo Ramat / Kummas Önsa Lutri / ja mu pühha Meeste Sure-Pühha-ja muid Jhho ning Hinge Häddas tarwiks tullejad Laulo leietakse. Riga: Johann Georg Wilcken.

Laulo-Ramat 1727 = Eesti-Ma-Rahwa Laulo-Ramat, Mis sees Önsa Lutterusse ja muud teised wannad ning ued kaunid Laulud on üllespandud.

Tarto-Ma kele Laulu-Ramat 1752. Tarto-Ma kele Laulu-Ramat, Kumman kik wanna nink wastse Laulo, kumma senni ajani Tükki Wärki trükkitu, ütte Ramato sisse omma kokko kootu, nink sündlikkuide Nimme alla säetu. Riga: Samuel Lorenz Wrölik.

\section{Kirjandus}

An n ist, August 1966. Friedrich Reinhold Kreutzwaldi muinasjuttude algupära ja kunstiline laad. Tallinn: Eesti Raamat.

E i s e n, Matthias Johann 1926. Eesti vana usk. Tartu: Eesti Kirjanduse Selts. 
EKSS = Eesti keele seletav sõnaraamat. IV köide P - R. Eesti Keele Insituut. Tallinn: Eesti Keele Sihtasutus, 2009.

H u p e l, August Wilhelm 1780. Ehstnische Sprachlehre für beide Hauptdialekte den revalschen und den dörptschen; nebst einem vollständigen Wörterbuch. Riga und Leipzig: Johann Friedrich Hartknoch.

K i n g i s e p p, Valve-Liivi, R e s s, Kristel, T a f e n a u, Kai 2010. Heinrich Gösekeni grammatika ja sõnastik. Tartu: Tartu Ülikooli eesti ja üldkeeleteaduse instituut.

M a s i n g, Uku 1999 [1962]. Martin Gilläuse „Ehstnische Sprachbemerkungen”. Uku Masing, Eesti vanema kirjakeele lood. Tartu: Ilmamaa, lk 91-99.

M a s in g, Uku, S o o s a a r, Albert 1999 [1956]. Kolme sajandi eest värsistatud lauluraamatust. - Uku Masing, Eesti vanema kirjakeele lood. Tartu: Ilmamaa, lk 59-90.

M ä g e r, Mart 1971. Riimi üldküsimusi. - Looming, nr 1, lk 123-132.

$\mathrm{N}$ e i t h a l, Reet 2005. Reiner Brockmannist ja eesti (tõlke)luule vanusest. - Keel ja Kirjandus, nr 2, lk 92-98.

P a u l, Hermann 1966. Deutsches Wörterbuch. Bearbeitet von Werner Betz. 6 . Auflage. Unveränderte Studienausgabe nach der 5., völlig neu bearbeiteten und erweiterten Auflage. Tübingen: Max Niemeyer Verlag.

Piiblikonverentsid 2003 = Piiblikonverentsid ja keelevaidlused. Põhjaeestikeelse Piibli tõlkimise ajaloost (1686-1690). Allikapublikatsioon. Koost Leino Pahtma, Kai Tafenau. Toim Jürgen Beyer. (Ex fontibus archivi historici Estoniae.) Tartu: Eesti Ajalooarhiiv.

R u p p r i c h, Hans 1973. Die deutsche Literatur vom späten Mittelalter bis zum Barock. Zweiter Teil. Das Zeitalter der Reformation 1520-1570. München: Beck.

S a a r e s t e, Andrus 1958-1963. Eesti keele mõisteline sõnaraamat. Stockholm: Vaba Eesti.

Salu, Herbert 1949. Zur Entwicklung des estnischen Kirchenliedes im 17. Jahrhundert. - Pühendusteos Eesti Vabariigi Tartu Ülikoolile tema avamise /1. detsember 1919/ kolmekümnendaks mälestuspäevaks paguluses viibivate õppejõudude ja kasvandikkude poolt. Stockholm: Eesti Teaduslik Selts Rootsis, lk 79-87.

S a n g, Joel, V i k s, Ülle 1991. Riimisõnastiku sünnist. - Keel ja Kirjandus, nr 10, lk 614-617.

T a f e n a u, Kai 2011. Ex ignorantia linguae ridiculus sensus. Eestikeelsete tekstide kriitikast 17. sajandi lõpul. - Lugemise kunst. Koost Piret Lotman. (Eesti Rahvusraamatukogu toimetised 13.) Tallinn: Eesti Rahvusraamatukogu, lk 123-150.

V a lk, Ülo 1994. Kurat Euroopa usundiloos. Sissejuhatus demonoloogiasse. Tallinn: Vikerkaar.

V is n a p u u, Henrik 1932. Tähelepanekuid ja märkmeid riimist. - Looming, $\mathrm{nr} 3$, lk 311-322.

V õ õ b u s, Arthur 1970. Eesti kirikulaulu algusest ja selle kujunemisest. - Oma Kirik, nr 6, lk 15-21.

W i e d e m a nn, Ferdinand Johann 1869. Ehstnisch-deutsches Wörterbuch. St. Petersburg: Kaiserliche Akademie der Wissenschaften. 


\section{A creature born by force of rhyme}

Keywords: history of written Estonian, translation of church hymns, rhyme

The article focuses on a nominal phrase or compound word invented by the translators of the first versified Estonian church hymnal (1656). Although the German versions of Lutheran church hymns had end rhyme, the hymns used to be translated into Estonian in prose and without any rhyme up to the mid-17th century. The translators of the hymnal of 1656 were the first to employ meter and rhyme following the strict versification rules established by Martin Opitz. In order to find pure rhymes various tricks were used. In five hymns, the frequent verb form on ('is, are, have, has') was rhymed with the conspicuous phrase porrgu konn 'toad of hell' as a synonym for 'the Devil'. Although Martin Luther had indeed compared the devil to the toad, the corresponding compound word *Höllenfrosch or *Höllenkröte was unfamiliar in Lutheran German. Even the translators themselves seem to have had doubts about the Estonian phrase and it was mocked by the critics of the first hymnal. From later hymnals the phrase was eliminated, but it had probably already found its way to the vernacular. Since the end of the $18^{\text {th }}$ century it has been registered in dictionaries. In the middle of the 19th century the author of the most famous collection of Estonian fairy tales F. R. Kreutzwald created his well known pseudomythological creature põhja konn 'Toad of the North' probably inspired by the same phrase.

Kristiina Ross (b. 1955), PhD, Institute of the Estonian Language, senior researcher, kristiina.ross@eki.ee 